\title{
Foreword
}

\section{The International Symposium on Smart Aircraft - A Special Issue}

In July 2019, the Aerospace Education Forum was held in Manchester, organised in collaboration with Xi'an Jiaotong University (XJTU), a C9 League (China's Ivy League) university, and the University of Manchester Aerospace Research Institute (UMARI), which plays a vital role in positioning the university at the forefront of international aerospace research by creating an environment where collaboration can take place easily and is becoming a collaborator of choice within Europe and for major aerospace companies. Currently over 100 academics and researchers make up the membership of the institute. In addition to traditional aeronautics, Manchester has a strong heritage of space research, encompassing the pioneering radio astronomy work at Jodrell Bank as well as planetary science and cosmochemistry, space instrumentation and space technology development. During this two-day event (24-25 July 2019), invited speakers from the UK and abroad presented and discussed education matters related to aerospace engineering at graduate and postgraduate level, including student individual and group projects, degree accreditation by professional institutions, national centres for doctoral training (CDT), women in aerospace, breaking stereotypes and social responsibility in science and engineering. Social responsibility lies at the heart of what we do at Manchester and describes the way we are making a difference to the social and environmental wellbeing of our communities through our teaching, research, public events and activities.

The primary objective of the Manchester workshop was to provide an excellent basis for world-leading teaching and research training and collaboration in the field of aerospace science and engineering, and more specifically to strengthen collaboration with leading universities from Europe, China and beyond and develop ideas to attract a young generation to the aerospace sector in both academia and industry. It was also agreed to explore possibilities of mutual educational programmes, summer schools and research with joint $\mathrm{PhD}$ supervision in aerospace science and engineering.

The Aerospace Education Forum was followed by a two day international conference on 'Smart Aircraft', hosted by Dr Gang Chen in Xi' an at the new campus of Jiaotong University. From this conference gelled the idea of a special issue of The Aeronautical Journal, whereby invited guest editors would choose from amongst the leading key speakers of the conference to publish their latest work. Conference delegates had the privilege of listening to invited talks from prominent researchers who responded with much enthusiasm and aplomb in the presentation of 100 papers. Selected papers focus on the application of the fundamentals of aerodynamic optimisation and the design principles of smart morphing Unmanned Aerial Vehicles (UAV) to the micro-mechanics of composite materials across a wide range of size scales of structural integrity, from events that occur in the material to future trends in the predictive design of large-scale aircraft structures. Papers on rotorcraft systems for urban air 


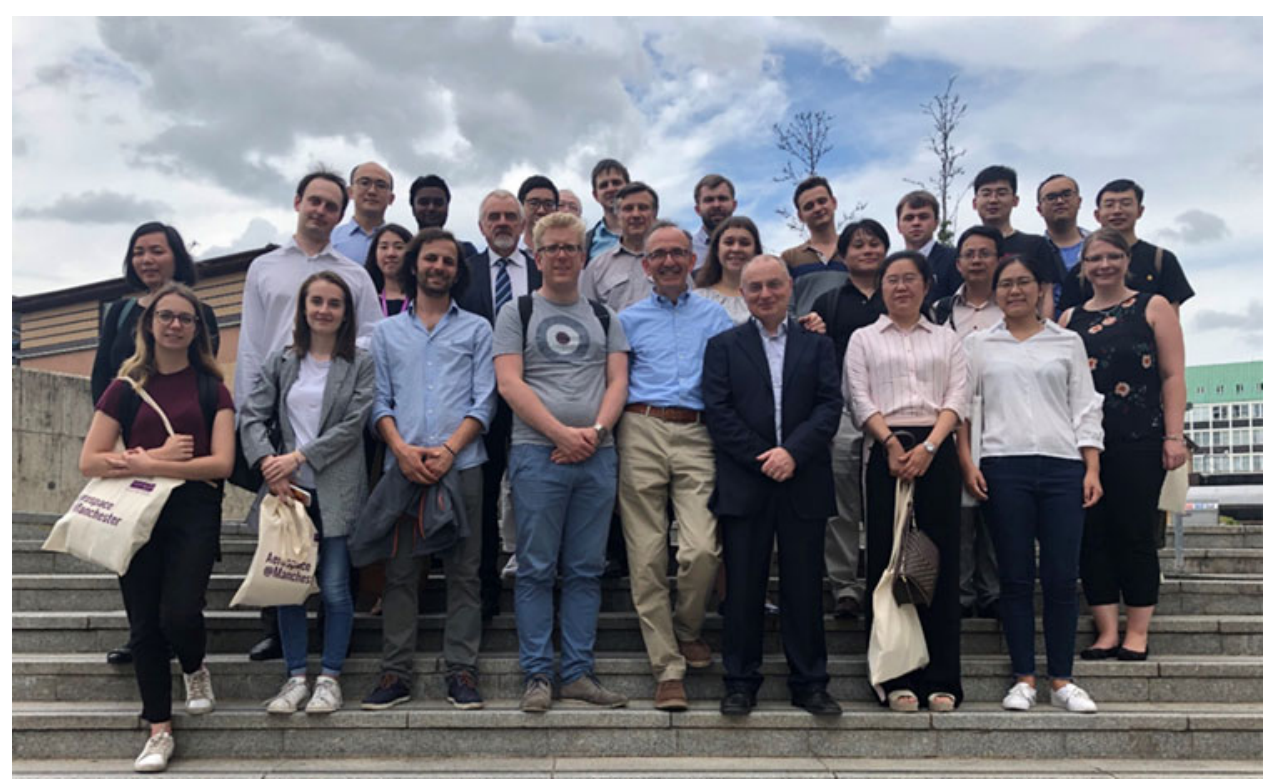

Professor Costas Soutis (middle of front row) with some of the delegates of the Aerospace Education Forum held in Manchester on 24-25 July 2019.

mobility, endurance improvement by battery damping strategy and vibration suppression of a microsatellite with flexible appendages based on smart structures can be found in addition to microwave energy for curing and damage sensing of aircraft composite structures. Modern numerical modelling of thin anisotropic composite membranes that could lead to considerable weight reductions for smart aerospace structures and the development of a fire detection and suppression system for smart air cargo container are also presented.

We take this opportunity to thank the writers and the reviewers of these papers. We thank them for their support and giving of their time in writing their papers. We also thank Professor Holger Babinsky, the Editor-in-Chief of The Aeronautical Journal, for giving us the opportunity to produce this special issue and the editorial support staff, Ms Annabel Hallam and Mr Wayne J Davis, for their continuing assistance throughout the assembly of these papers and compilation of this special issue.

\section{Guest Editors}

Professor Costas Soutis Manchester University

Professor Gang Chen Xi'an Jiaotong University 